\title{
Parameters of wood welding: A study with infrared thermography
}

\author{
Christelle Ganne-Chédeville1,2, Milena \\ Properzi ${ }^{1, \star}$, Antonio Pizzi ${ }^{2}$, Jean-Michel Leban ${ }^{3}$ \\ and Frédéric Pichelin'
}

\author{
${ }^{1}$ Berner Fachhochschule, University of Applied \\ Sciences HSB, Biel, Switzerland \\ 2 ENSTIB-LERMAB, University of Nancy 1, Epinal, \\ France \\ ${ }^{3}$ INRA, Institut National de la Recherche Agronimique, \\ Centre de Champenoux, Champenoux, France \\ ${ }^{*}$ Corresponding author. \\ Berner Fachhochschule, University of Applied Sciences HSB, \\ Solothurnstrasse 102, P.O. Box CH-2500, Biel-Bienne 6, \\ Switzerland \\ E-mail: milena.properzi@bfh.ch
}

\begin{abstract}
Welding of wood is a well-known joining procedure that offers several advantages over traditional mechanical fasteners or gluing. During welding, extensive solid-state transformation phases occur in the so-called melting zone and the heat-affected zone. The nature and the extension of such transformations are correlated to the energy input and thus to the heat generated during the process at the wood joint interface. In the present work the influence of the welding parameters and wood grain orientation on the temperature profile and distribution and final strength of welded connections was investigated. For this purpose, the characteristics of the joints were evaluated with both destructive and non-destructive techniques. Non-destructive evaluation was performed with infrared thermography, which allowed measurement of the maximal and average peak temperature, temperature profile and distribution, and rate of temperature increase. Thus, this technique can also be used to detect welding defects and to provide information on material modification during welding.
\end{abstract}

Keywords: camera for infrared thermography; infrared thermography; wood grain; wood melting; wood welding.

\section{Introduction}

Welding is a novel joining procedure that offers advantages over gluing and mechanical fasteners. This technique is widely used in the plastics industry and was shown to be effective when used in combination with thermoplastic and thermosetting adhesives for wood bonding (Gerber and Gfeller 2000).

The first investigation on wood welding without any bonding agent was carried out in Germany in 1996 (Sutthoff et al. 1996). Later, Gliniorz et al. (2001) reported on the utilisation of friction welding for wood-to-wood welding as an innovative process with high potential for development. The first attempt at wood welding by linear vibration friction welding was carried out at the HSB in 2002 (Gfeller et al. 2004). It was demonstrated that the manufacture of high-quality, environmentally friendly wood joints is possible without any adhesive or any additional chemicals. Adhesion of wood surfaces by vibration welding is accompanied by a considerable increase in wood density at the bonded interface (Leban et al. 2004). This is the result of the melting and flowing of amorphous polymers such as lignins and hemicelluloses (Gfeller et al. 2004).

The energy input, and thus the heat generated at the joint interface, plays a key role in the chemical/physical processes leading to the final strength of the welded joint (Lin et al. 1999). Accordingly, rapid and accurate measurement of the peak joint temperature and cooling rate is necessary. This is a difficult task because the heat generated is rapidly conducted into deeper layers. Infrared thermography, which is a two-dimensional non-contact technique for surface temperature mapping, seems to be an attractive method for determination of the overall heating flow during welding (Wikle et al. 2001). The effectiveness of IR thermography for on-line sensing and weld-process monitoring is extensively documented in the literature (Wang and Chin 1986; Banerjee et al. 1993; Davé et al. 2001; Wikle et al. 2001; Meola et al. 2004; Venkatraman et al. 2005). This technique allows the assessment of transient temperature changes, even with short response times. Experiments showed that measurements using thermocouples are disturbed by vibration, as the contact between electrode and wood became loose (Gfeller and Properzi 2003; Gfeller et al. 2004), and thus IR thermography is more suitable.

The aim of this study was to gain more information on the dynamics of microstructure development in the course of vibration welding. The influence of the welding parameters should be investigated in terms of interrelations between the wood anatomy and microstructure, welding temperature and final strength of the joint.

\section{Materials and methods}

\section{Preparation of the joints}

Two maple (Acer campestre L.) specimens with dimensions of $150 \times 20 \times 30 \mathrm{~mm}^{3}$ were welded together to form cubes of $150 \times 20 \times 60 \mathrm{~mm}^{3}$ with a welded area of $3000 \mathrm{~mm}^{2}$. The welded connections were manufactured with cuts in either tangential (grain angle $0^{\circ}$ ) or radial (grain angles $45^{\circ}$ and $90^{\circ}$ ) grain orientations (Figure 1). Ten pairs of specimens were welded for each test series. The specimens had a density of $610-640 \mathrm{~kg} \mathrm{~m}^{-3}$, annual ring thickness of $2-3.5 \mathrm{~mm}$ and roughness $\left(R_{\mathrm{a}}\right.$, measured with a Mitutoyo Surftest 211 instrument) of 2.3-4 $\mu \mathrm{m}$. The spec- 


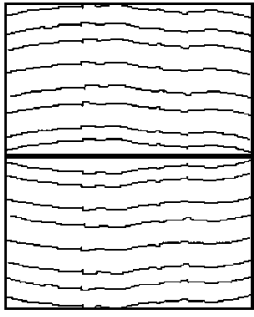

$0^{\circ}$

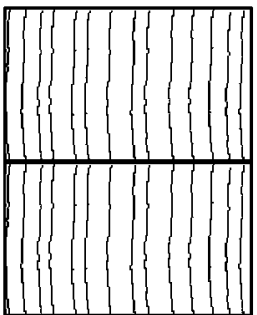

$90^{\circ}$

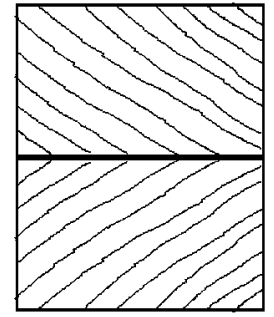

$45^{\circ}$
Figure 1 Grain orientation in the welded joints. From left to the right: specimen welded in the tangential grain orientation $\left(0^{\circ}\right)$, and specimens welded in the radial grain orientation $\left(90^{\circ}\right.$ and $\left.45^{\circ}\right)$.

imens were conditioned in a climate camber $\left(20^{\circ} \mathrm{C}\right.$ and $\left.65 \% \mathrm{RH}\right)$ to $12 \%$ equilibrium moisture content (EMC) before welding.

The equipment used was a Branson 2700 linear vibration welding machine (LVWM). A frequency (F) of $100 \mathrm{~Hz}$ and an amplitude $(A)$ of $3 \mathrm{~mm}$ was applied. The parameters were previously optimised (Properzi et al. 2005) to a welding time (WT) of $4 \mathrm{~s}$ and holding time $(\mathrm{HT})$ of $5 \mathrm{~s}$. The welding and holding pressure (WP and $\mathrm{HP})$ were adjusted to $1.5 \mathrm{MPa}\left(\mathrm{N} \mathrm{mm}^{-2}\right)$.

\section{Mechanical characterisation: tensile-shear test}

The tensile shear strength was measured according to European Standard EN 205 (2003). Prior to the tests, specimens were cut to a final thickness of $10 \mathrm{~mm}$. The welded connections $\left(200 \mathrm{~mm}^{2}\right)$ were then tested in tension on a Zwick model 1454 universal testing machine at a rate of $6 \mathrm{~mm} \mathrm{~min}^{-1}$.

\section{Infrared thermography}

A Flir ThermaCAM ${ }^{\circledR}$ S60 infrared thermography (IRT) camera was used, which has a sensitivity of $0.08^{\circ} \mathrm{C}$ at $30^{\circ} \mathrm{C}$ for a frequency of $50 \mathrm{~Hz}$. The detector installed on the camera was a focal plane array (FPA) with uncooled microbolometers. The infrared spectral range was between 7.5 and $13 \mu \mathrm{m}$ and the temperature range was $-40^{\circ} \mathrm{C}$ to $+500^{\circ} \mathrm{C}$. All parameters (reflected ambient temperature, distance, relative humidity, atmospheric transmission, and external optic) are automatically corrected. The camera was positioned at a distance of $370 \mathrm{~mm}$ from the specimen surface. The conditions for measurements were $20^{\circ} \mathrm{C}$ and $50 \% \mathrm{RH}$. Each welding cycle was recorded from $2 \mathrm{~s}$ before to $2 \mathrm{~s}$ after the vibration period. The resolution was 50 pictures $\mathrm{s}^{-1}$. Thermacam Researcher software provided by Flir was used for data evaluation.

\section{X-Ray microdensitometry analyses}

Sections of $1.88 \pm 1 \mathrm{~mm}$ in thickness were obtained for each sample, conditioned at $12 \%$ moisture content, and tested by $\mathrm{X}$-ray microdensitometry. The equipment consisted of an X-ray tube producing soft rays at a low energy level with long-wave characteristics emitted through a beryllium window. The distance from the tube was $2.5 \mathrm{~m}$. This distance is important to

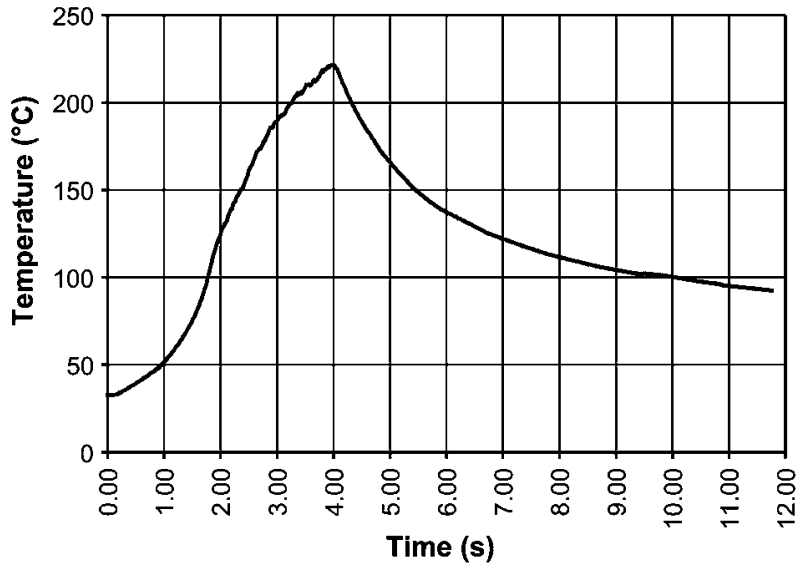

Figure 2 Profile of temperature increase during welding for a joint manufactured with wood cut in the longitudinal radial $\left(45^{\circ}\right)$ grain orientation with a welding time (WT) of $4 \mathrm{~s}$; HT, holding time.

minimise blurring of the image on the film frame used (in this case $18 \times 24 \mathrm{~cm}^{2}$ ). Typical exposure conditions were $4 \mathrm{~h}, 7.5 \mathrm{~kW}$ and $12 \mathrm{~mA}$. Two calibration samples were placed on each negative photograph to calculate the wood density. Specimens were tested in this manner on a set-up consisting of an electric generator (Inel XRG3000), an X-ray tube (Siemens FK60-04 Mo, $60 \mathrm{kV}, 2.0 \mathrm{~kW}$ ), and a Kodak film negative (Industrex M100).

\section{Optical microscopy analyses}

A Leica DMLM 25-500 $\times$ optical microscope with digital image capture and analysis was used to obtain information on the characteristics of the welded region. Based on the images recorded, the interdependence between the temperature gradient, density profile, microstructure and final joint strength was determined. A specimen of $20 \times 15 \times 10 \pm 1 \mathrm{~mm}^{3}$ was obtained from each welded joint and incorporated into a matrix of epoxy resin. After the resin was cured, the specimen was polished by sanding. For each grain orientation (Figure 1) 10 specimens (with surface dimensions of $20 \times 15 \pm 1 \mathrm{~mm}^{2}$ ) were analysed using IM 1000 software.

\section{Results and discussion}

Infrared thermography is an accurate, non-contact measurement technique that is well suited for monitoring the temperature distribution beneath the surface of specimens to be welded (Gfeller and Properzi 2003). Figure 2 illustrates the temperature increase as a function of time (temperature profile) for a joint manufactured with wood cut in the longitudinal-radial $\left(45^{\circ}\right)$ grain orientation (Figure 1). During the welding time (WT, 0-4 s) the temperature increased from $32^{\circ} \mathrm{C}$ to $223^{\circ} \mathrm{C}$ at a rate of $47.5^{\circ} \mathrm{C} \mathrm{s}^{-1}$. However, it is clearly evident from Figure 2 that the rate

Table 1 Tensile-shear strength (TS) according to European Standard EN205, with maximal temperature (MT) and maximal average temperature (MAT) measured after $4 \mathrm{~s}$ of welding at a different average temperature increase rate (TIR).

\begin{tabular}{lccccc}
\hline Species & Grain orientation & $\begin{array}{c}\text { TS } \\
(\mathrm{MPa})\end{array}$ & $\begin{array}{c}\mathrm{MT} \\
\left({ }^{\circ} \mathrm{C}\right)\end{array}$ & $\begin{array}{c}\text { MAT } \\
\left({ }^{\circ} \mathrm{C}\right)\end{array}$ & $\begin{array}{r}\text { TIR } \\
\left({ }^{\circ} \mathrm{C} \mathrm{s}^{-1}\right)\end{array}$ \\
\hline Maple & Tangential $\left(0^{\circ}\right)$ & $6.5 \pm 1.6$ & $265 \pm 3$ & $216 \pm 6.4$ & 45.7 \\
Maple & Radial $\left(90^{\circ}\right)$ & $8.1 \pm 0.8$ & $284 \pm 8$ & $223 \pm 10.5$ & 47.5 \\
Maple & Radial $\left(45^{\circ}\right)$ & $9.0 \pm 0.9$ & $282 \pm 13$ & $223 \pm 6.2$ & 47.5 \\
\hline
\end{tabular}

Each result reported in the table is the average of 10 tests \pm standard deviation. 


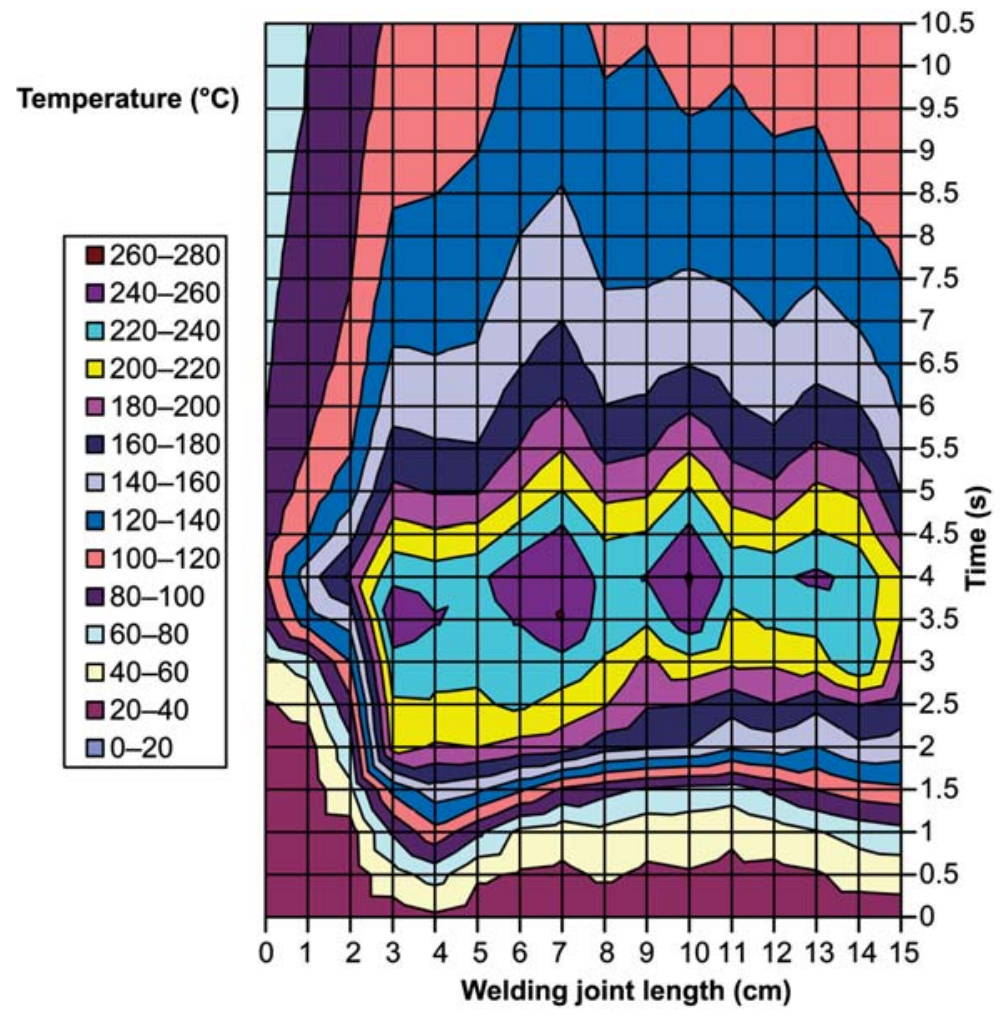

Figure 3 Temperature profile over the whole joint length, with wood cut in the longitudinal radial $\left(45^{\circ}\right)$ grain orientation. The welding time (WT) was $4 \mathrm{~s}$ and the holding time $(\mathrm{HT})$ was $5 \mathrm{~s}$.

of temperature increase was not constant. It took approximately $1 \mathrm{~s}$ to reach a temperature of $50^{\circ} \mathrm{C}$ at a rate of $19^{\circ} \mathrm{C} \mathrm{s}^{-1}$. In the following $2 \mathrm{~s}$, the temperature increased rapidly at $69^{\circ} \mathrm{C} \mathrm{s}^{-1}$ until it reached $180^{\circ} \mathrm{C}$. The rate of increase slowed down during the last $1 \mathrm{~s}\left(30^{\circ} \mathrm{C}\right.$ $\mathrm{s}^{-1}$ ) and the curve seems to take a logarithmic form up to a limit of approximately $220^{\circ} \mathrm{C}$. Similar temperature ranges were previously obtained by placing thermocouples at the welding interface of beech joints welded under similar conditions (Gfeller et al. 2004). Similar temperature values (approx. $230^{\circ} \mathrm{C}, 500 \mathrm{~K}$ ) were reported by other authors in the context of circular friction welding (4 s) (Stamm et al. 2005). Figure 2 illustrates that during the 5 -s holding time $(\mathrm{HT})$, the temperature decreased from $220^{\circ} \mathrm{C}$ to $100^{\circ} \mathrm{C}$. A few minutes later, the specimen had cooled down to room temperature. Similar temperature profiles were noted for specimens welded in the longitudinal-tangential grain orientation (Table 1).

According to the literature (Sundqvist 2004), modifications in the range $40-90^{\circ} \mathrm{C}$ (WT 0-1 s) are mainly due to physical changes, such as the loss of water and volatiles, accompanied only by minor chemical changes. In

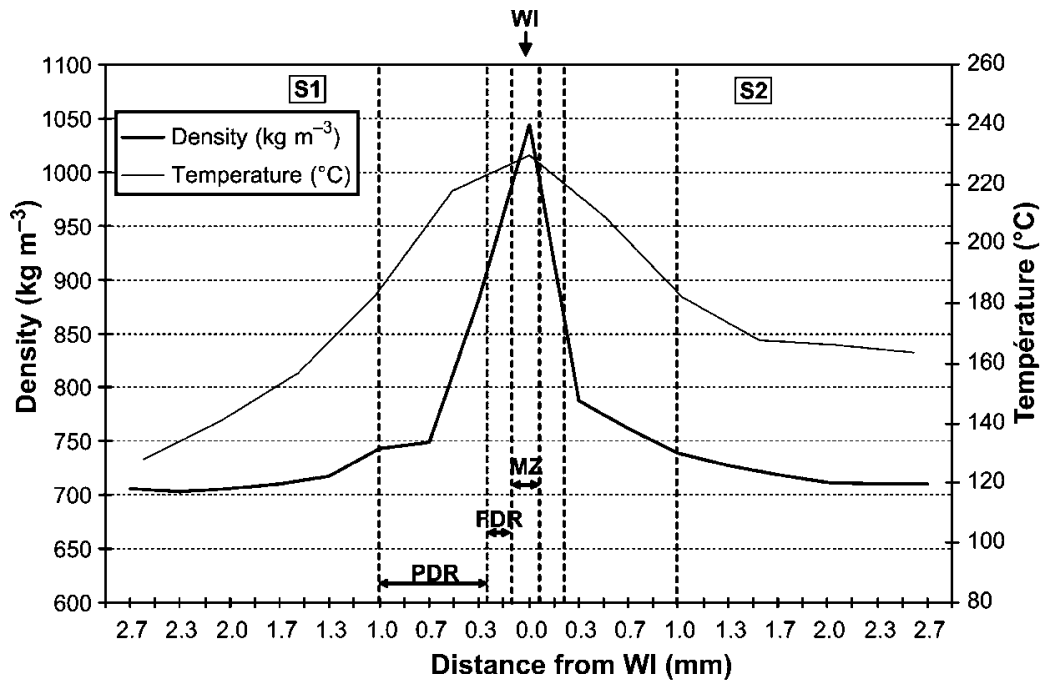

Figure 4 Density profile, microscopy image (transversal cut section) and temperature distribution perpendicular to the welding surface for a joint manufactured with wood cut in the longitudinal radial $\left(90^{\circ}\right)$ grain orientation, showing the welding interface $(\mathrm{WI})$, heat-affected zone (HAZ), partially deformed region (PDR), fully plasticised and deformed region (FDR) and melting zone (MZ). 
Table 2 Influence of the wood grain orientation on the thickness of the heat-affected zone (HAZ), melting zone (MZ), fully plasticised and deformed region (FDR) and partially deformed region (PDR).

\begin{tabular}{|c|c|c|c|c|c|}
\hline \multirow[t]{2}{*}{ Species } & \multirow[t]{2}{*}{ Grain orientation } & \multicolumn{4}{|c|}{ Thickness ( $\mu \mathrm{m})$} \\
\hline & & $M Z$ & FDR & PDR & HAZ \\
\hline Maple & Tangential $\left(0^{\circ}\right)$ & $61 \pm 14$ & $89 \pm 12$ & $191 \pm 32$ & $312 \pm 44$ \\
\hline Maple & Radial $\left(90^{\circ}\right)$ & $155 \pm 41$ & $172 \pm 44$ & $825 \pm 87$ & $1076 \pm 186$ \\
\hline Maple & Radial $\left(45^{\circ}\right)$ & $90 \pm 18$ & $132 \pm 34$ & $282 \pm 95$ & $453 \pm 86$ \\
\hline
\end{tabular}

Each result reported in the table is the average of 10 tests \pm standard deviation.

the range $90-180^{\circ} \mathrm{C}(\mathrm{WT} 1-3 \mathrm{~s})$ more pronounced changes occur, as both softwoods and hardwoods have softening temperatures close to $180^{\circ} \mathrm{C}$ (WT $3 \mathrm{~s}$ ). However, moisture lowers the softening temperature. Thermal conversion starts and damage to wood structures is visible at temperatures above $200^{\circ} \mathrm{C}$ (WT 3-4 s). True pyrolysis begins at temperatures higher than $270^{\circ} \mathrm{C}$ (Fengel and Wegener 2003). Thus, based on the maximal temperature (MT) values indicated in Table 1, we suggest that both melting and thermal conversion of wood components occur during welding.

IRT also allows observation of the temperature changes along the joint length, as shown in Figure 3. The isotherms in this graph allow a global evaluation of the temperature profile and the identification of maximal peak temperatures and cooling rates.

Table 1 shows that the MT measured during welding for specimens tangentially oriented was lower than the temperature for the other specimens. The results also indicate that there is a positive correlation between MT, the maximal average temperature (MAT), the temperature increase rate (TIR), and the mechanical strength of the joints. Within the scope of the parameters investigated, it was found that better mechanical strength can be obtained at higher temperatures (Table 1). Based on these results, we suggest that tangential grain orientation in maple is less favourable for welding. This could be related to the ratio of early to late wood in the welding surfaces. In the tangential direction, this ratio is lower than in the radial direction. It was previously demonstrated that in the case of rotational wood-dowel welding,

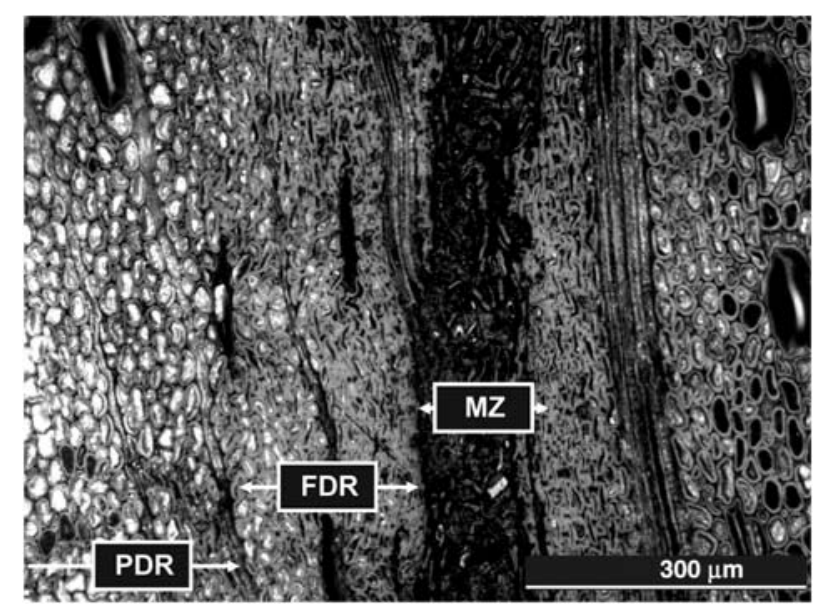

Figure 5 Optical microscopy section of a joint manufactured with wood cut in a longitudinal radial $\left(90^{\circ}\right)$ grain orientation, showing details of the partial deformed region (PDR), fully plasticised and deformed region (FDR); melting zone (MZ). interfacial densification is greater in regions where the wood had a higher density (Ganne-Chédeville et al. 2005). In linear vibration welding, the phenomenon might be similar, which means that at lower wood density the resistance of the joint is also lower.

Optical microscopy and X-ray microdensitometry allow microstructural analysis of joints (Leban et al. 2004) in both the melting zone (MZ) and the heat-affected zone (HAZ). Based on Figures 4 and 5, the HAZ can be subdivided into three sub-zones. (1) A fully plasticised and deformed region (FDR), where the cell lumen is still visible, but is occasionally totally closed. When the thermomechanical stress exceeds a certain limit, the plasticised wall collapses (Pichelin et al. 2000). (2) A partially deformed region (PDR) is also perceptible, where the elastic buckling deformation of wood cells is predominant, and (3) an undeformed region (UR). Table 2 shows the influence of grain orientation on the HAZ thickness. Thus, the HAZ is thinner in specimens welded in the tangential $\left(0^{\circ}\right)$ than in the radial $\left(90^{\circ}\right.$ and $\left.45^{\circ}\right)$ grain orientation. For fixed welding parameters and radial grain orientation $\left(90^{\circ}\right)$, it can be noted (Table 2 and Figure 4) that the $\mathrm{MZ}$ is approximately $155 \mu \mathrm{m}$ thick, as previously shown by other techniques (Wieland et al. 2005). The total extent of the HAZ is approximately $1076 \mu \mathrm{m}$, with the FDR $172 \mu \mathrm{m}$ and the PDR approximately $825 \mu \mathrm{m}$. At distances greater than $1076 \mu \mathrm{m}$ from the welding line, no density changes or anatomical modifications are evident.

Polymers in a transition state between the glassy and rubbery phases are susceptible to permanent plastic deformation and cellular collapse (Kulticova 1999). In this context, it is reasonable to conclude that during welding the $\mathrm{HAZ}$ reaches temperatures higher than $180^{\circ} \mathrm{C}$. This hypothesis is confirmed by the temperature profile measured after $4 \mathrm{~s}$ of welding time, as illustrated in Figure 4.

\section{Conclusions}

Infrared thermography is suitable for monitoring the temperature during welding. IRT delivers information on the maximal and average peak temperature, temperature profile and rate of temperature increase. Welding defects can also be detected, and information on material modifications during welding can be deduced.

By comparing temperature profiles and the tensileshear strength of specimens welded with different grain orientations, it has been found that these parameters are correlated. Tangential grain orientation of maple is less favourable than radial grain orientation. 
Various HAZs have been identified. The extent and characteristics of the HAZs influence the final proprieties of the welded joints. The interdependence between the welding parameters, especially the temperature, and the physico-chemical characteristics of the heated region needs further investigation.

\section{Acknowledgements}

The authors would like to thank Dipl. Ing. Christian Rogenmoser of the HSB, Switzerland for his help with the optical microscopy investigations.

\section{References}

Banerjee, P., Govardhan, S., Wikle, H.C., Liu, J.Y., Chin, B.A. (1993) Infrared sensing for on-line weld process monitoring and control. J. Manuf. Sci. Eng. 115:907-918.

Davé, V.R., Cola, M.J., Hussen, N.A. (2001) Heat generation in inertia welding of dissimilar tubes. Weld. J. Res. Suppl. 10:246-252.

European standard (2003) EN 205, Adhesives - Wood adhesives for non-structural applications. Determination of the tensileshear strength of lap joints.

Fengel, D., Wegener, G. (2003) Wood - Chemistry, Ultrastructure, Reactions. Verlag Kessel, Remagen, 2003.

Ganne-Chédeville, C., Pizzi, A., Thomas, A., Leban, J.-M., Bocquet, J.-F., Despres, A., Mansouri, H. (2005) Parameter interactions, two-block welding and the wood nail concept in wood dowels welding. J. Adhes. Sci. Technol. 19:1157-1174.

Gerber, C., Gfeller, B. (2000) Joint connection with welded thermoplastic dowels and Wood Welding Technologies. In: Proceedings of the World Conference on Timber Engineering, British Columbia, Canada.

Gfeller, B., Properzi, M. (2003) Woobration, CTI scientific report. BFH-HSB, Bienne, Switzerland.

Gfeller, B., Pizzi, A., Zanetti, M., Properzi, M., Pichelin, F., Lehmann, M., Delmotte, L. (2004) Solid wood joints by in situ welding of structural wood constituents. Holzforschung 58:45-52.

Gliniorz, K.U., Mohr, S., Natterer, J., Navi, P. (2001) Wood welding. In: Proceedings of the 1st International Conference of the European Society for Wood Mechanics, Lausanne, Switzerland.
Kulticova, E.V. (1999) Structure and proprieties relationship of densified wood. M.Sc. Thesis, Polytechnic Institute and State University, Blacksburg, VA, USA.

Leban, J.-M., Pizzi, A., Wieland, S., Zanetti, M., Properzi, M., Pichelin, F. (2004) X-Ray microdensitometry analysis of vibration-welded wood. J. Adhes. Sci. Technol. 18:673-685.

Lin, C.B., Mu, C.K., Wu, W.W., Hung, C.H. (1999) The effect of joint design and volume fraction on friction welding proprieties of A360/SiC (p) composites. Weld. J. Res. Suppl 3:100-108.

Meola, C., Squillace, A., Minutolo, F.M.C., Morace, R.E. (2004) Analysis of stainless steel welded joints: a comparison between destructive and non-destructive techniques. J. Mater. Process. Technol. 155:1893-1899.

Pichelin, F., Pizzi, A., Frühwald, A. (2000) Improving oriented strand board proprieties by using high moisture tolerant adhesives. In: Proceedings of the International Conference on Wood and Wood Fiber Composites, Otto-Graf-Institute, Stuttgart, Germany, pp. 429-438.

Properzi, M., Leban, J.-M., Pizzi, A., Wieland, S., Pichelin, F., Lehamann, M. (2005) Influence of the grain direction in vibrational wood welding. Holzforschung 59:23-27.

Stamm, B., Natterer, J., Navi, P. (2005) Joining of wood by friction welding. Holz Roh Werkst. 63:313-320.

Sundqvist, B. (2004) Colour change and acid formation in wood during heating. PhD. Thesis, Lulea University of Technology, Sweden.

Sutthoff, B., Franz, U., Hentschel, H., Schaaf, A. (1996) Verfahren zum reibschweissartigen Fügen und Verbinden von Holz. German Patent DE 19620273 C2.

Venkatraman, B., Baldev, R., Menaka, M. (2005) Online infrared detection of inclusions and lack of penetration during welding. Mater. Eval. 9:933-937.

Wang, Y., Chin, B.A. (1986) Online sensing of weld penetration using infrared thermography. Opt. Tech. Insp. 34:314-320.

Wieland, S., Shi, B., Pizzi, A., Properzi, M., Stampanoni, M., Abela, R., Lu, X., Pichelin, F. (2005) Vibration welding of wood: X-ray tomography, additives, radical concentration. For. Prod. J. 55:84-87.

Wikle, H.C., Kottilingam, R.H., Zee, R.H., Chin, B.A. (2001) Infrared sensing technique for penetration depth control of the submerged arc welding process. J. Mater. Process. Technol. 113:228-233.

Received August 19, 2005. Accepted March 21, 2006. 